\title{
Associations of pre- and postpartum lying time with metabolic, inflammation, and health status of lactating dairy cows
}

\author{
J. M. Piñeiro, ${ }^{1 *}$ B. T. Menichetti, ${ }^{1}$ A. A. Barragan, ${ }^{1} \dagger$ A. E. Relling, ${ }^{2}$ W. P. Weiss, ${ }^{2}$ S. Bas, ${ }^{1} \ddagger$ \\ and G. M. Schuenemann ${ }^{1} \S$ \\ ${ }^{1}$ Department of Veterinary Preventive Medicine, The Ohio State University, Columbus 43210 \\ ${ }^{2}$ Department of Animal Sciences, The Ohio State University, Wooster 44691
}

\section{ABSTRACT}

The objective was to evaluate the associations of pre- and postpartum lying time (LT) with serum total calcium (Ca), nonesterified fatty acids (NEFA), $\beta$-hydroxybutyrate (BHB), and haptoglobin concentrations, hemogram, and health status of dairy cows. A total of 1,052 Holstein cattle (401 nulliparous heifers and 651 parous cows) from 3 commercial dairy farms were fitted with electronic data loggers (IceQube, IceRobotics, Edinburgh, UK) on a hind leg $14 \pm 3 \mathrm{~d}$ before parturition (dpp) and removed at $14 \pm 3 \mathrm{~d}$ in milk (DIM) to assess their LT. Lying time data were summarized and reported daily $(\mathrm{min} / \mathrm{d}$ or $\mathrm{h} / \mathrm{d})$. Serum concentrations of NEFA (at $14 \pm 3$ and $7 \pm 3 \mathrm{dpp}$ ), total serum calcium within $48 \mathrm{~h}$ after calving, and BHB (at $7 \pm 3$ and $14 \pm 3$ DIM) were determined. Serum concentration of haptoglobin was determined and a hemogram was performed on a subsample of 577 cows (237 primiparous and 340 multiparous) at $7 \pm 3$ DIM. Cases of milk fever, retained placenta, metritis, mastitis, pneumonia, and digestive disorders within 30 DIM were recorded and cows were categorized into 1 of 4 groups: (1) nondiseased ( $\mathrm{ND}, \mathrm{n}=613$; cows without ketosis and any other health conditions); (2) cows with only ketosis (KET, $\mathrm{n}=152$ ); (3) sick cows experiencing $\geq 1$ health conditions, but without ketosis (SICK, $\mathrm{n}=198$ ); or (4) cows with ketosis plus at least one other health condition $(\mathrm{KET}+, \mathrm{n}=61)$. Data were analyzed using mixed linear regression models or logistic regression (MIXED or GLIMMIX procedures). Lying time within $14 \mathrm{dpp}$ had a significant positive quadratic association

Received July 15, 2018.

Accepted December 22, 2018.

*Current address: Texas A\&M AgriLife Research and Extension Center, Amarillo 79106.

$\dagger$ Current address: Department of Veterinary and Biomedical Sciences, Pennsylvania State University, University Park 16802.

$\ddagger$ Current address: Phytobiotics Futterzusatzstoffe GmbH, D-65343 Eltville, Germany.

§Corresponding author: schuenemann.5@osu.edu with serum NEFA concentrations at $14 \pm 3$ and $7 \pm$ 3 dpp but was not significantly associated with serum Ca concentration within $48 \mathrm{~h}$ after calving. Lying time during the first 14 DIM after parturition had a significant linear association with the risk of ketosis within 14 DIM. For every 1-h increment in mean LT (from 8 to $15 \mathrm{~h} / \mathrm{d}$ ) within the first 14 DIM after calving, the risk of diagnosis with ketosis within 14 DIM increased by 3.7 percentage points. Regardless of parity, a greater proportion of KET and KET+ groups had increased serum prepartum NEFA concentration $(\geq 400 \mu \mathrm{Eq} / \mathrm{L})$ and increased body condition loss from $14 \mathrm{dpp}$ to 28 DIM compared with SICK and ND cows. A greater proportion of multiparous KET and KET+ cows had hypocalcemia within $48 \mathrm{~h}$ after calving compared with ND and SICK cows, but we did not detect a significant association between hypocalcemia and health status on primiparous cows. Multiparous KET + cows had significantly reduced neutrophils and white blood cell count compared with ND cows, but lymphocytes did not differ. Regardless of parity, KET+ and SICK cows had significantly higher concentrations of serum haptoglobin compared with ND cows. These results suggest that LT along with energy and Ca balance are critical for transition cow health.

Key words: lying time, inflammation, health, dairy cattle

\section{INTRODUCTION}

The periparturient period (approximately 3 wk before and after calving) poses the highest risk for developing diseases and mortality in dairy cows. During the early postpartum period, approximately 1 out of 2 cows will experience at least one adverse health event (Ferguson, 2005 ), with nearly $75 \%$ of all disease cases occurring during this period (LeBlanc et al., 2006). Infectious and metabolic diseases result in direct and indirect costs that negatively affect the profitability of dairy operations (Rollin et al., 2015; Gohary et al., 2016). Moreover, these diseases are detrimental to animal wel- 
fare and lead to early removal of cows and increased antimicrobial usage. Therefore, efforts should focus on controlling the risk factors and the prevention of diseases (e.g., consistency of DM intake, feed within reach of animals) to reduce production losses, improve animal well-being, and decrease the use of antimicrobials in dairy farms. Metabolic diseases, such as hypocalcemia and hyperketonemia, have been showed to impair the immune response, increase the risk for diseases, and reduce reproductive performance (Kimura et al., 2006; Martinez et al., 2012; Zarrin et al., 2014).

Cows have a strong behavioral need to rest, spending approximately half of their time lying down (Munksgaard et al., 2005; Gomez and Cook, 2010). Cows deprived from lying down show endocrinological alterations, with increased ACTH and decreased growth hormone plasma concentrations, which is associated with stress events and decreased milk production, respectively (Munksgaard and Løvendahl, 1993; Munksgaard and Simonsen, 1996). In addition, decreased lying time (LT) and increased time standing in the stall have been shown to increase sole lesions and lameness (Galindo and Broom, 2000; Gomez and Cook, 2010). Moreover, restricting $\mathrm{LT}$ alters feeding behavior, reducing feeding time and increasing feeding rate and meal size, which in turn may result in increased ruminal acid production and digestive disorders (Allen, 1997; Munksgaard et al., 2005). However, the effects of LT during the transition period on metabolic stress, inflammation and health have not yet been fully investigated.

We hypothesized (1) that reduced LT ( $\mathrm{min} / \mathrm{d}$ or $\mathrm{h} / \mathrm{d}$ ) within $14 \mathrm{~d}$ before parturition would be associated with increased prepartum nonesterified fatty acids (NEFA) and decreased postpartum serum total Ca concentrations; and (2) that increased LT within 14 DIM would be associated with increased serum BHB concentrations, increased inflammatory response, and increased incidence of diseases within 30 DIM. Therefore, the objectives of this study were to assess the associations of LT $14 \mathrm{~d}$ before and after parturition with serum Ca, NEFA, and BHB concentrations, inflammation (haptoglobin and hemogram), and health status within the first 30 DIM.

\section{MATERIALS AND METHODS}

\section{Animals and Facilities}

A total of 1,052 pregnant Holstein animals (401 nulliparous heifers, 278 primiparous and 373 multiparous cows) from 3 commercial dairies selected by convenience (housed cows in freestall barns) and located in central Ohio were used for this prospective observational study. Cohorts of 20 to 36 pregnant heifers and cows were enrolled for 2 consecutive weeks, at each farm, every 5 wk for a 1-yr period. Farms were visited twice weekly. At enrollment, a list of prepartum heifers and cows 14 $\pm 3 \mathrm{~d}$ before the expected parturition date (dpp, $262 \pm$ 3 d of gestation; Vieira-Neto et al., 2017) was obtained using on-farm computer records (Dairy Comp 305, Valley Agricultural Software, Tulare, CA).

Briefly, on farm 1, pregnant heifers and cows were grouped separately during the prepartum period and commingled during the postpartum period, housed in 4-row freestall barns with deep recycled manure bedding, and fed a TMR twice daily at 0700 and $1230 \mathrm{~h}$ during summer and once daily at $0700 \mathrm{~h}$ during the rest of the year. On farms 2 and 3, pregnant heifers and cows were grouped together (commingled) during the pre- and postpartum periods, housed in 6-row freestall barns with deep sand bedding, and fed a TMR once daily at $0900 \mathrm{~h}$. All farms grouped their animals at dryoff (60 to $22 \mathrm{dpp}$ ), at prepartum (21 dpp), and at postpartum (up to 21 DIM), and had high (22-150 DIM) and low (>150 DIM) milk yield pens for their lactating cows. Dairy heifers and cows were fed a TMR to meet or exceed dietary nutritional requirements (NRC, 2001; Tables 1 and 2). The ingredient and nutrient compositions of formulated pre- and postpartum diets (DM basis) were reported by farm. On farms 1 (1,300 dairy cows) and 2 (1,500 dairy cows), cows were milked 3 times daily in a double-20 parallel and double-24 herringbone parlor, respectively. On farm 3 (2,700 dairy cows), cows were milked 4 times daily during the early postpartum period in a double-32 parallel parlor. All farms used natural ventilation and had fans on their pens and holding area before the milking parlor for heat abatement. During the study period, the average daily milk yields per cow were 36,29 , and $35 \mathrm{~kg} / \mathrm{d}$ for farms 1, 2 and 3, respectively.

Calving events such as dystocia and stillbirth were recorded (Schuenemann et al., 2011). Body condition score (5-point scale with 0.25-unit increments; Ferguson et al., 1994) and locomotion score (LS; $1=$ sound, $2=$ mildly lame, $3=$ moderately to severely lame; as described by Walker et al., 2008) were assessed at 14 dpp and at $14 \pm 3$ and $28 \pm 3$ DIM. Change in BCS was calculated for each cow by subtracting the BCS at $14 \pm 3$ dpp from that at $28 \pm 3$ DIM. This study was conducted from August 2016 through February 2018. The procedures described below were reviewed and approved by The Ohio State University Institutional Animal Care Use Committee.

\section{Hemogram, Haptoglobin, and Metabolite Assays}

Blood samples were collected via coccygeal venipuncture using $8-\mathrm{mL}$ evacuated tubes by 2 members of the 
Table 1. Ingredients composition (\% of DM) of pre- and postpartum diets by farms

\begin{tabular}{|c|c|c|c|c|c|c|}
\hline Ingredient & \multicolumn{3}{|c|}{ Prepartum } & \multicolumn{3}{|c|}{ Early postpartum } \\
\hline Grass hay & - & 14.9 & - & - & 4.6 & - \\
\hline Haylage & - & - & - & - & 9.5 & 5.1 \\
\hline Alfalfa hay & - & - & - & 4.8 & - & 5.1 \\
\hline Canola meal light & 14.1 & - & - & 13.1 & - & - \\
\hline Mineral mix & 7.4 & 2.0 & 5.9 & 4.8 & 2.3 & 0.8 \\
\hline Soybean hulls & - & - & - & 11.8 & 5.8 & - \\
\hline Whey protein & - & - & - & 7.6 & 2.1 & 15.9 \\
\hline Soybean meal & - & 4.7 & 8.3 & 6.0 & 9.5 & 8.9 \\
\hline Distiller grains & - & 11.2 & 7.2 & - & 4.2 & 8.7 \\
\hline Fruit waste & - & 4.7 & - & - & 2.1 & - \\
\hline Triticale silage & - & - & - & - & 11.6 & - \\
\hline
\end{tabular}

research team (J. M. Piñeiro and B. T. Menichetti) and farm personnel (calcium). Blood samples were obtained from all pre- and postpartum heifers and cows for determination of serum NEFA (at $14 \pm 3$ and $7 \pm 3 \mathrm{dpp}$ ), total serum calcium within $48 \mathrm{~h}$ after calving, and BHB at $7 \pm 3$ and $14 \pm 3$ DIM (Figure 1). From a subset of 577 cows (237 primiparous and 340 multiparous) at 7 \pm 3 DIM, blood samples were collected to assess their serum haptoglobin concentrations and hemogram. The first blood sample was collected into evacuated tubes with EDTA (BD Vacutainer, Franklin Lakes, NJ) and stored at $4^{\circ} \mathrm{C}$; the hemogram was performed within 4 $\mathrm{h}$ after collection, using a VetScan HM5 hematology analyzer (Abaxis, Union City, CA) to assess lymphocytes, neutrophils, and total white blood cells count (WBCC). The second blood samples were collected into evacuated tubes without anticoagulant for determination of serum haptoglobin concentration with a commercially available bovine haptoglobin ELISA kit (Life Diagnostics, West Chester, PA). All blood samples for analyses of serum metabolites and haptoglobin concentration were obtained from coccygeal blood vessels into evacuated tubes without anticoagulant and centrifuged at $3,100 \times g$ for $15 \mathrm{~min}$ at room temperature within $4 \mathrm{~h}$ after collection. Immediately after this, measurements of serum concentrations of BHB were obtained (Nova Biomedical, Billerica, MA). A case of ketosis was defined as a serum concentration of BHB $\geq 1.2 \mathrm{mmol} / \mathrm{L}$ (McArt et al., 2012a; Kaufman et al., 2016) from at least one blood sample $(7 \pm 3$ or $14 \pm$ 3 DIM). Afterward, all serum samples were stored at $-20^{\circ} \mathrm{C}$ until assayed. Samples for determination of serum NEFA [NEFA-HR(2), Wako Chemicals, Richmond, VA], and total serum calcium (Calcium Liquicolor No. 0150, Stanbio Laboratory, Boerne, TX) were analyzed using 96-well plates, and absorbance were measured at

Table 2. Nutrient composition (\% of DM unless otherwise noted) of formulated pre- and postpartum diets by farms

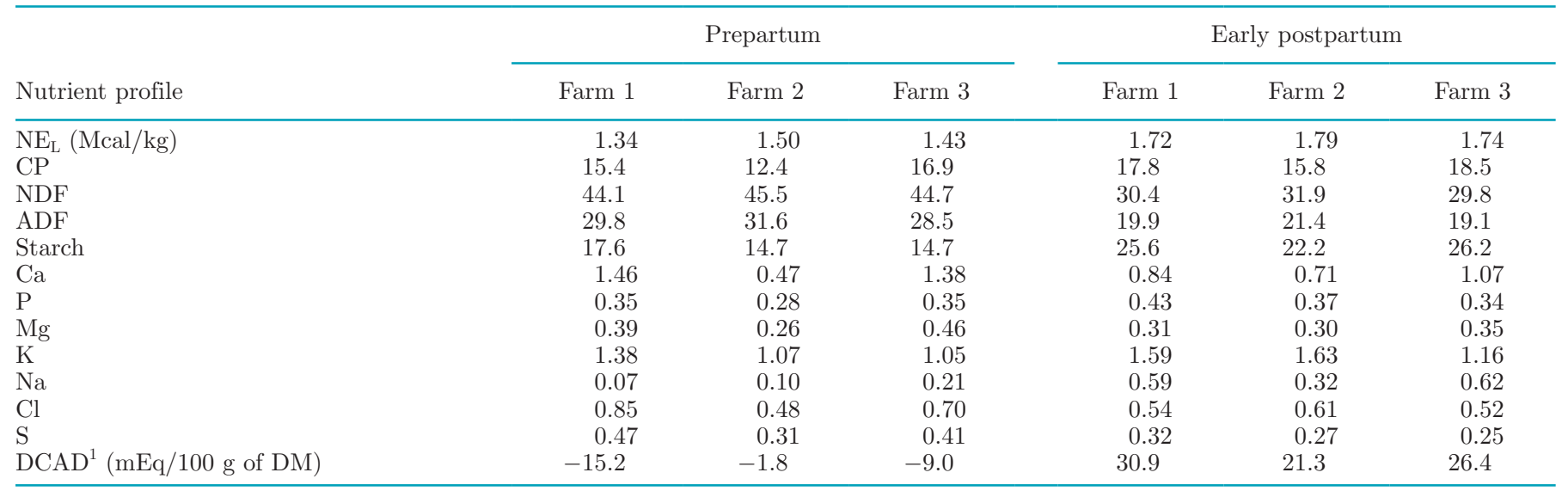

${ }^{1}$ Calculated as follows: $(\mathrm{mEq}$ of $\mathrm{Na}+\mathrm{mEq}$ of $\mathrm{K})-(\mathrm{mEq}$ of $\mathrm{S}+\mathrm{mEq}$ of $\mathrm{Cl})$. 
$550 \mathrm{~nm}$ with a Bio-Tek Microplate Reader (Bio-Tek Instruments, Winooski, VT). A case of hypocalcemia was defined as a serum concentration of total $\mathrm{Ca}<8.0$ $\mathrm{mg} / \mathrm{dL}$ within $2 \mathrm{~d}$ after parturition (Reinhardt et al., 2011). For determination of serum concentrations of haptoglobin, absorbance was measured at $450 \mathrm{~nm}$ using a Multiskan MCC/340 plate reader (Thermo Labsystems, Mountain View, CA). The intra- and interassay coefficients of variation for serum concentrations of NEFA, Ca, and haptoglobin were 3.8 and $2.0 \%, 4.0$ and $2.3 \%$, and 17.8 and $14.7 \%$ respectively.

\section{Diagnosis of Health Events}

Data pertaining to postpartum diseases within the first 30 DIM (e.g., retained fetal membranes, left displaced abomasum, clinical mastitis, digestive and respiratory disorders) were obtained from on-farm computer records (DairyComp 305, Valley Agricultural Software). Farm personnel responsible for the health program received training by G. M. Schuenemann (on-farm workshop followed by hands-on demonstrations) on case definitions of health events and recording before the start of the study. Briefly, farm personnel performed a health screening of early postpartum cows (within the first $4 \mathrm{wk}$ after calving) every morning after the first milking. Clinical examination included changes in milk yield (first morning milking), assessment of vaginal discharge and presence of fetal membranes outside the vulva, and signs of dehydration such as sunken eyes, attitude, and rumen fill. Lactating cows experiencing any observed sign of illness such as a sudden drop in milk yield or abnormal vaginal discharge were subject to a thorough hands-on examination (as- sessment of rectal temperature, rectal palpation, and abdominal and thoracic auscultation and percussion). Retained fetal membranes was defined as the failure to expel fetal membranes $24 \mathrm{~h}$ after calving. Left displaced abomasum was defined as the translocation of the abomasum to an abnormal position on the left side of the abdomen characterized by a "ping" sound at auscultation while performing digital percussion. All cows were examined at $7 \pm 3$ DIM for metritis by the research team. Metritis was defined as a fetid, watery, red-brown uterine discharge with or without pyrexia (Sheldon et al., 2006). Lactating cows experiencing cases of clinical mastitis (abnormal milk secretion with presence of flakes or clots with or without swollen udder) were identified by farm milkers during the milking routine. To assess the association of lying time with ketosis, other transition diseases or ketosis and other diseases combined, lactating dairy cows were classified into 1 of 4 groups with regards to their postpartum health status: (1) nondiseased (cows without ketosis or any other diagnosed health conditions; ND); (2) cows diagnosed with only ketosis (KET); (3) cows experiencing $\geq 1$ health conditions but without ketosis (SICK); or (4) cows with ketosis plus at least 1 health condition (KET+; Kaufman et al., 2016).

\section{Assessment of Lying Time of Transition Cows}

Electronic data loggers (IceQube, IceRobotics, Edinburgh, UK) were placed on a hind leg of prepartum heifers and cows at $14 \mathrm{dpp}$ and removed at $14 \pm 3$ DIM to assess their LT over time. Data from individual animals were exported from IceManager software to an Excel spreadsheet (Microsoft Corp., Redmond, WA).

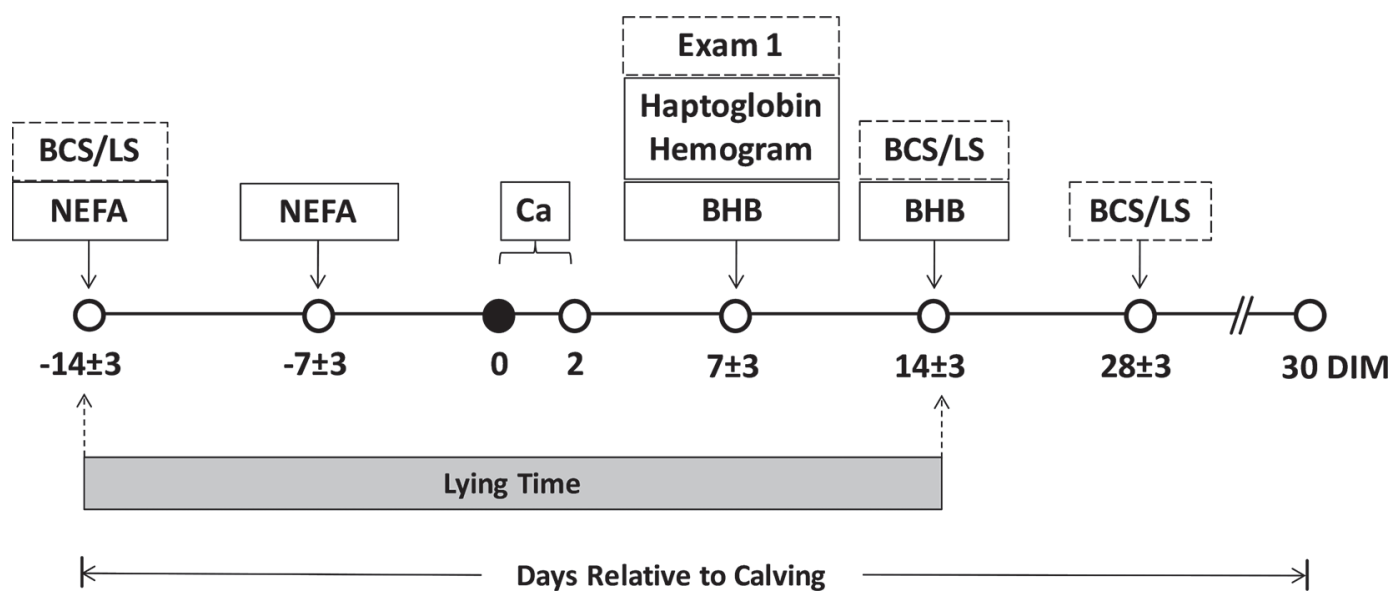

Figure 1. Schematic representation showing the timeline for data collection relative to calving. Pregnant Holstein heifers and cows $(\mathrm{n}=$ 1,052) were fitted with an electronic data logger on a hind leg at $14 \pm 3 \mathrm{~d}$ before calving (d 0), which was removed at $14 \pm 3$ DIM to assess lying time. Closed boxes represent blood samples obtained to assess serum concentration of metabolites (NEFA = nonesterified fatty acids; Ca = total serum calcium), haptoglobin, and hemogram. Dashed boxes represent the assessment of BCS (using a 5-point scale); locomotion score (LS, using a 3-point scale); and clinical examination of metritis (exam 1 at $7 \pm 3 \mathrm{DIM}$ ). 
Lying time data were summarized and reported daily as $\operatorname{LT}(\mathrm{min} / \mathrm{d}$ or $\mathrm{h} / \mathrm{d})$.

\section{Statistical Analyses}

Data from individual prepartum heifers and lactating dairy cows (e.g., parity, health events, and calving date) were exported from DairyComp 305 into an Excel spreadsheet. Data regarding LT, serum concentrations of haptoglobin, and WBCC (neutrophils, lymphocytes, and total leukocytes), were assessed for normality of the residuals once obtained from their respective final model using the Shapiro-Wilk statistic (histograms and Q-Q plots, PROC UNIVARIATE of SAS; SAS Institute, 2014). Due to lack of normality, $\log _{10}$ transformations were performed on lymphocyte and total leukocyte counts, and fourth root transformations were performed on neutrophil counts and serum haptoglobin concentrations.

Association of Pre- and Postpartum Lying Time with Health Status. The association of daily LT with health status (KET, KET+, SICK, and ND) $14 \pm 3 \mathrm{~d}$ before and $14 \pm 3 \mathrm{~d}$ after parturition was analyzed using mixed linear regression model (MIXED procedures of SAS; SAS Institute, 2014) with days relative to parturition used as repeated measures. Lying time was considered the outcome variable and the predictor variables offered to the model included health status, parity (lactation $=1$ or lactations $\geq 2$ ), BCS at $14 \mathrm{dpp}, \mathrm{LS}$ at $14 \mathrm{dpp}(1=$ sound, $2=$ mildly lame, 3 $=$ moderately to severely lame) hypocalcemia within 48 $\mathrm{h}$ after parturition (yes, $<8.0 \mathrm{mg} / \mathrm{dL}$ or no, $\geq 8.0 \mathrm{mg} /$ dL; Reinhardt et al., 2011), and season (fall, winter, spring, summer). Herd was included as a random effect. Nonsignificant variables were eliminated manually from the model one at a time using the Wald statistic backward selection criterion $(P>0.15)$ because of their lack of effect on the outcome variable. The final model included the effects of health status, parity, LS at $14 \mathrm{dpp}$, and herd. First-order autoregressive [AR(1)] covariance structure was used to account for the correlated data structure between the repeated daily measurements within animals $(14 \mathrm{~d}$ before and $14 \mathrm{~d}$ after parturition). Additionally, the health status $\times$ parity and health status $\times$ day interactions were tested. The differences in least squares means of LT among the 14 $\mathrm{d}$ before and after parturition were computed by including the PDIFF option in the LSMEANS statement. Mean comparisons were carried out using the TukeyKramer method. Data pertaining to the association of LT with parity groups (lactation $=1$ or lactations $\geq 2$ ) $14 \mathrm{~d}$ before and the first 14 DIM after parturition were analyzed using mixed linear regression models (MIXED procedures of SAS; SAS Institute, 2014).
Association of Prepartum LT with Serum NEFA and Ca. The association of LT within 14 dpp with serum NEFA concentrations prepartum and hypocalcemia $(<$ or $\geq 8.0 \mathrm{mg} / \mathrm{dL})$ within $48 \mathrm{~h}$ after parturition were analyzed using mixed linear regression or logistic regression models (MIXED or GLIMMIX procedures of SAS, respectively; SAS Institute, 2014). For the analysis, the mean LT within 14 dpp was grouped by hour intervals (e.g., cows with a mean LT between 480 and $540 \mathrm{~min} / \mathrm{d}$ were grouped together and then reported as $8 \mathrm{~h} / \mathrm{d}$ interval). Cows with mean LT below $8 \mathrm{~h} / \mathrm{d}$ or above $16 \mathrm{~h} / \mathrm{d}$ were coded as $<8$ and $>16 \mathrm{~h} / \mathrm{d}$, respectively. Models for each outcome of interest (NEFA and hypocalcemia) included parity (lactation $=1$ or lactations $\geq 2$ ), BCS at $14 \mathrm{dpp}$, LS at $14 \mathrm{dpp}$, season (fall, winter, spring, summer), and mean LT within $14 \mathrm{dpp}$ as predictor variables. Herd was included as a random effect. Nonsignificant variables were eliminated from the model one at a time using the Wald statistic backward selection criterion $(P>0.15)$. Regarding the association of LT within 14 dpp (hour intervals) with NEFA, the final model included the effect of season and parity to obtain the adjusted least squares means ( \pm SEM). Using this model, the linear and quadratic $(\mathrm{LT} \times \mathrm{LT})$ association was assessed.

Association of Postpartum LT with Ketosis, Haptoglobin, and Neutrophil Count. The association of LT within 14 DIM with inflammation (haptoglobin and neutrophils) as well as with the diagnosis with ketosis (yes or no) within 14 DIM were assessed using mixed linear regression (MIXED) or logistic regression analyses using GLIMMIX procedures of SAS, respectively (SAS Institute, 2014). For the analyses, mean LT within 14 DIM was grouped by hour intervals as described above. For ketosis, the model included parity, BCS at $14 \mathrm{dpp}$, season, and LS at $14 \mathrm{dpp}$ as predictor variables. For haptoglobin and neutrophil count, each model included parity, health status, and season as predictor variables. Herd was included as a random effect. Nonsignificant variables were eliminated from the model one at a time using the Wald statistic backward selection criterion $(P>0.15)$. Regarding the association of LT within 14 DIM (hour intervals) with ketosis, the final model included the effect of season and parity to obtain the adjusted least squares means ( \pm SEM). Using this model, the linear and quadratic $(\mathrm{LT} \times \mathrm{LT})$ association was assessed. In addition, the least squares means of LT by hour intervals were obtained from the final model and plotted against ketosis (\%) and the coefficient of variation (CV) of LT within the first 14 DIM. The CV of LT was computed for each animal by dividing the SD over LT mean within the first 14 DIM and reported as an absolute ratio. 
Association of Health Status with BCS Loss, NEFA, Ca, Haptoglobin, and Leukocyte Count. The association of BCS loss between $14 \pm 3 \mathrm{dpp}$ and $28 \pm 3$ DIM, WBCC, and haptoglobin with health status (KET, KET+, SICK, and ND) within 30 DIM by parity group were analyzed using mixed linear regression models (MIXED procedures of SAS; SAS Institute, 2014). The association of serum NEFA $(<$ or $\geq 400 \mu \mathrm{Eq} / \mathrm{L})$ and hypocalcemia within 2 DIM $(<$ or $\geq 8.0 \mathrm{mg} / \mathrm{dL}$; Reinhardt et al., 2011) with health status within 30 DIM by parity group were analyzed using logistic regression analyses (GLIMMIX procedure of SAS; SAS Institute, 2014). The critical thresholds used to dichotomize serum NEFA was based on the increased risk of metritis in cows with serum concentrations $\geq 400 \mu \mathrm{Eq} / \mathrm{L}$ (Ospina et al., 2013). A univariate model was performed for each variable, such as NEFA at $7 \mathrm{dpp}(<$ or $\geq 400 \mu \mathrm{Eq} / \mathrm{L})$, hypocalcemia within 2 DIM (yes, $<8.0 \mathrm{mg} / \mathrm{dL}$ or no, $\geq 8.0 \mathrm{mg} / \mathrm{dL}$ ), units of BCS loss between $14 \pm 3 \mathrm{dpp}$ and $28 \pm 3 \mathrm{DIM}$, WBCC, and haptoglobin concentration at 7 DIM on health status. For all models, herd was included as a random effect, and mean comparisons were carried out using the Tukey-Kramer method. Least squares means $( \pm$ SEM $)$ were reported. For analysis performed with transformed data, back transformed LSM and 95\% confidence intervals were presented.

For all models, nonsignificant variables were eliminated from the model one at a time using the Wald statistic backward selection criterion $(P>0.15)$. This $P$-value was selected because season $(P=0.14)$ had an effect of $>10 \%$ on the mean of one outcome variable (culling); thus, it was retained in the model because of its biological importance as $10 \%$ is equivalent to roughly $1 \mathrm{~h}$ of LT per day (it is also a known confounder). All other variables retained in the models were $P<0.05$. A $P<0.05$ was considered statistically significant for all statistical analyses.

\section{RESULTS}

A total of 1,024 Holstein heifers and cows were included in the final analyses. Twenty-eight cows were excluded from the study [3 cows did not calve during the study period due to late abortion or incorrect conception date, and 25 cows were sold $(\mathrm{n}=9)$ or died $(\mathrm{n}=16)$ before the first health screening at $7 \pm 3$ DIM]. Because dams were enrolled weekly $( \pm 3 \mathrm{~d})$, only $9.8 \%$ of dams out of 1,024 total animals used in the study had 1 to $2 \mathrm{~d}$ of missing data because they calved earlier than expected. The distribution of heifers and cows by parity, season, and health status is presented in Table 3. The distribution of prepartum and calving events as well as postpartum diseases by health status is presented in Table 4 .

\section{Lying Time and Health Status}

The effects of health status (variable of primary interest), parity, and LS on lying time (outcome variable) at 14 dpp remained in the final model. Multiparous cows had greater $(P<0.0001)$ LT before and after parturition compared with primiparous cows (Figure 2). During early lactation, the behavior of ND was characterized by a decrease in LT of 1 to $3 \mathrm{~h} / \mathrm{d}$ compared with the prepartum period (Figure 2). Prepartum heifers

Table 3. Distribution of Holstein dairy cows within 3 herds by parity (lactations 1,2 , and $\geq 3$ ), season (fall, winter, spring, and summer), and health status within $30 \mathrm{DIM}^{1}$

\begin{tabular}{lcccc}
\hline Items & Herd 1 & Herd 2 & Herd 3 & $P$-value \\
\hline Lactation 1 (no.) & 121 & 143 & 137 & \\
Lactation 2 (no.) & 119 & 69 & 91 & \\
Lactation $\geq 3$ (no.) & 117 & 167 & 88 & \\
Fall (no.) & 65 & 76 & 96 & \\
Winter (no.) & 101 & 92 & 85 & \\
Spring (no.) & 101 & 100 & 73 & \\
Summer (no.) & 90 & 111 & & \\
Health status within 30 DIM & & & & \\
ND (\%) & $69.8 \pm 2.5^{\mathrm{c}}$ & $49.3 \pm 2.5^{\mathrm{a}}$ & $61.4 \pm 2.7^{\mathrm{b}}$ & $<0.0001$ \\
KET (\%) & $10.4 \pm 1.9^{\mathrm{b}}$ & $18.8 \pm 1.8^{\mathrm{a}}$ & $9.3 \pm 2.0^{\mathrm{b}}$ & 0.0004 \\
KET+ (\%) & $3.1 \pm 1.2^{\mathrm{b}}$ & $8.8 \pm 1.2^{\mathrm{a}}$ & $5.1 \pm 1.3^{\mathrm{ab}}$ & 0.007 \\
SICK (\%) & $14.1 \pm 2.1^{\mathrm{b}}$ & $21.3 \pm 2.0^{\mathrm{a}}$ & $22.9 \pm 2.2^{\mathrm{a}}$ & 0.008 \\
\hline
\end{tabular}

${ }^{a-c}$ Least squares means with different superscript letters within the same row are significantly different.

${ }^{1}$ A total of 1,052 Holstein dairy heifers and cows from 3 herds were included in the analysis from August 2016 to July 2018. The number of animals by parity and seasons are shown.

${ }^{2}$ Least squares means $( \pm \mathrm{SEM})$ of the proportion $(\%)$ of lactating cows $(\mathrm{n}=1,024)$ diagnosed with ketosis only (KET, $\mathrm{n}=152)$, ketosis and at least 1 more health event diagnosed $(\mathrm{KET}+, \mathrm{n}=61$ ), at least one health event other than ketosis (SICK, $\mathrm{n}=198)$, and nondiseased cows (ND, $\mathrm{n}=613)$. 
Table 4 . Distribution of calving-related events ${ }^{1}$ by health groups in lactating dairy cows

\begin{tabular}{|c|c|c|c|c|}
\hline Item & $\begin{array}{c}\text { KET } \\
(\mathrm{n}=152)\end{array}$ & $\begin{array}{c}\mathrm{KET}+ \\
(\mathrm{n}=61)\end{array}$ & $\begin{array}{c}\text { SICK } \\
(\mathrm{n}=198)\end{array}$ & $\begin{array}{c}\text { ND } \\
(\mathrm{n}=613)\end{array}$ \\
\hline \multicolumn{5}{|l|}{ Prepartum and calving events (\%) } \\
\hline Lameness at $14 \operatorname{dpp}^{2}(\mathrm{n}=134)$ & 19.7 & 8.2 & 12.6 & 12.1 \\
\hline Dystocia $^{3}(\mathrm{n}=47)$ & 4.6 & 14.8 & 7.1 & 2.8 \\
\hline $\operatorname{Stillbirth}^{4}(\mathrm{n}=42)$ & 4.6 & 3.3 & 10.1 & 2.1 \\
\hline \multicolumn{5}{|l|}{ Postpartum health events (\%) } \\
\hline Retained fetal membranes $(\mathrm{n}=49)$ & - & 27.9 & 16.2 & - \\
\hline Milk fever $(\mathrm{n}=3)$ & - & 0 & 1.5 & - \\
\hline Ketosis $(\mathrm{n}=213)$ & 100 & 100 & - & - \\
\hline Metritis $(\mathrm{n}=193)$ & - & 70.5 & 75.8 & - \\
\hline Mastitis $(\mathrm{n}=37)$ & - & 14.8 & 14.1 & - \\
\hline Pneumonia $(\mathrm{n}=7$ ) & - & 1.6 & 3.0 & - \\
\hline Digestive disorders $^{5}(\mathrm{n}=15)$ & - & 13.1 & 3.5 & - \\
\hline
\end{tabular}

${ }^{1}$ The distribution (no.) of prepartum, calving, and postpartum health events by health status of lactating cows diagnosed with ketosis only (KET), ketosis and at least one more health event (KET+), at least one health event other than ketosis (SICK), and nondiseased cows (ND).

${ }^{2}$ Locomotion score $(1=$ sound, $2=$ mildly lame, $3=$ moderately to severely lame $)$ was assessed at $14 \mathrm{~d}$ before parturition (dpp). Prepartum lameness scores were not included in the criteria to classify the health status of postpartum cows.

${ }^{3}$ Dystocia was defined as difficult birth resulting in assisted extraction of the calf at birth.

${ }^{4}$ Stillbirth was defined as a calf born dead or died within $24 \mathrm{~h}$ after birth with a normal gestation length.

${ }^{5}$ Digestive disorders included lactating displaced abomasum, peritonitis or indigestion.

slowly decreased their LT starting $10 \mathrm{~d}$ before calving, whereas multiparous cows only decreased their LT starting $2 \mathrm{~d}$ before calving (Figure 2). Lying time was significantly associated with health status (Figure 3). There was a significant interaction between parity and health status on the effect on LT; therefore, multiparous and primiparous cows were analyzed separately. During the first $6 \mathrm{~d}$ after parturition, multiparous KET+ cows significantly increased their LT compared with multiparous ND cows (Figure 3). In addition, multiparous
KET and SICK cows had greater LT compared with multiparous ND cows at 2, 3, and 4 DIM (Figure 3). However, LT was not associated with health status for primiparous cows (Figure 3).

\section{Association of LT with Serum NEFA, Ca, and Ketosis}

The prevalence of hypocalcemia was $42.3 \%$ in multiparous cows and $19.9 \%$ in primiparous cows. Lying time of prepartum heifers and cows within 14 dpp was

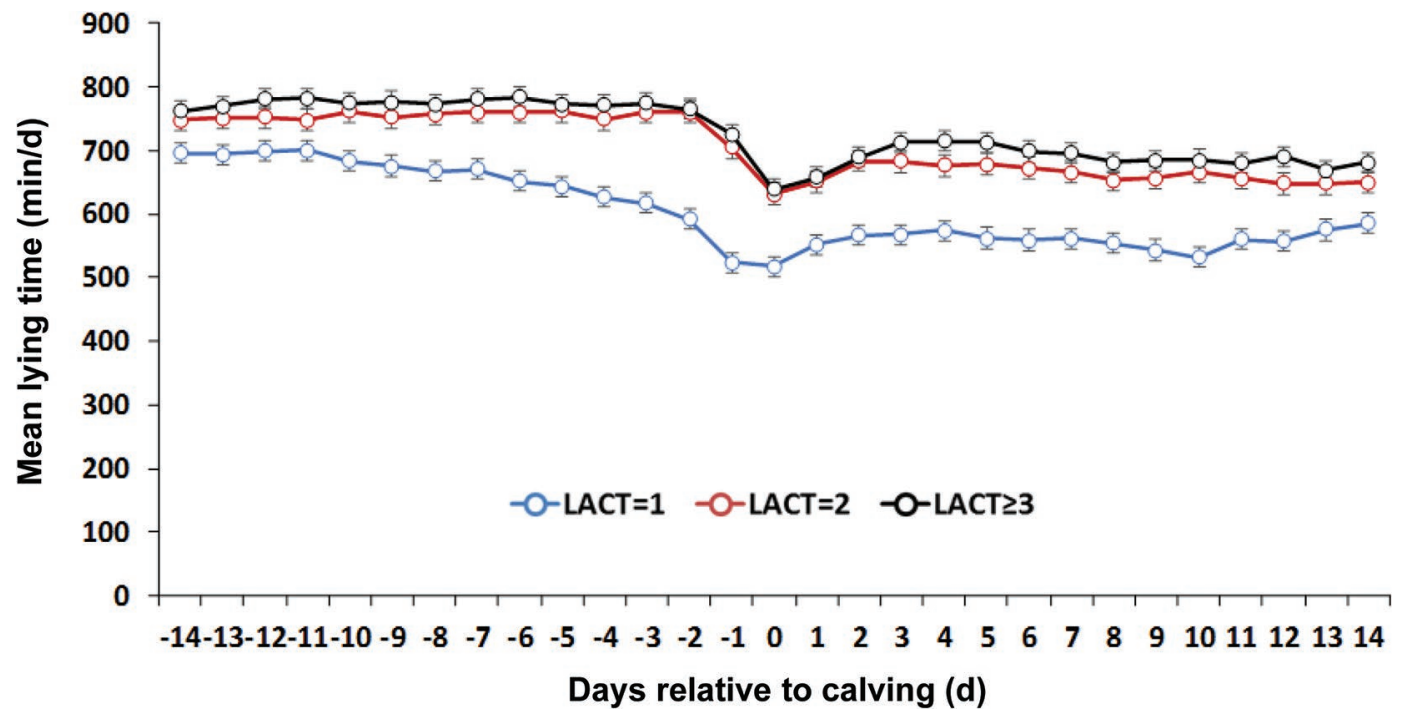

Figure 2. Mean lying time ( $\mathrm{min} / \mathrm{d} ; \pm \mathrm{SEM})$ of pre- and postpartum nondiseased (ND) Holstein dairy heifers $($ lactation $=1)$ and cows (lactation $=2$ and lactations $\geq 3)$ within the study period. Multiparous ND cows (LACT $=2$ or LACT $\geq 3)$ had significantly greater $(P<0.0001)$ lying time compared with primiparous ND cows (LACT $=1$; prepartum heifers) during the pre- and postpartum period. 


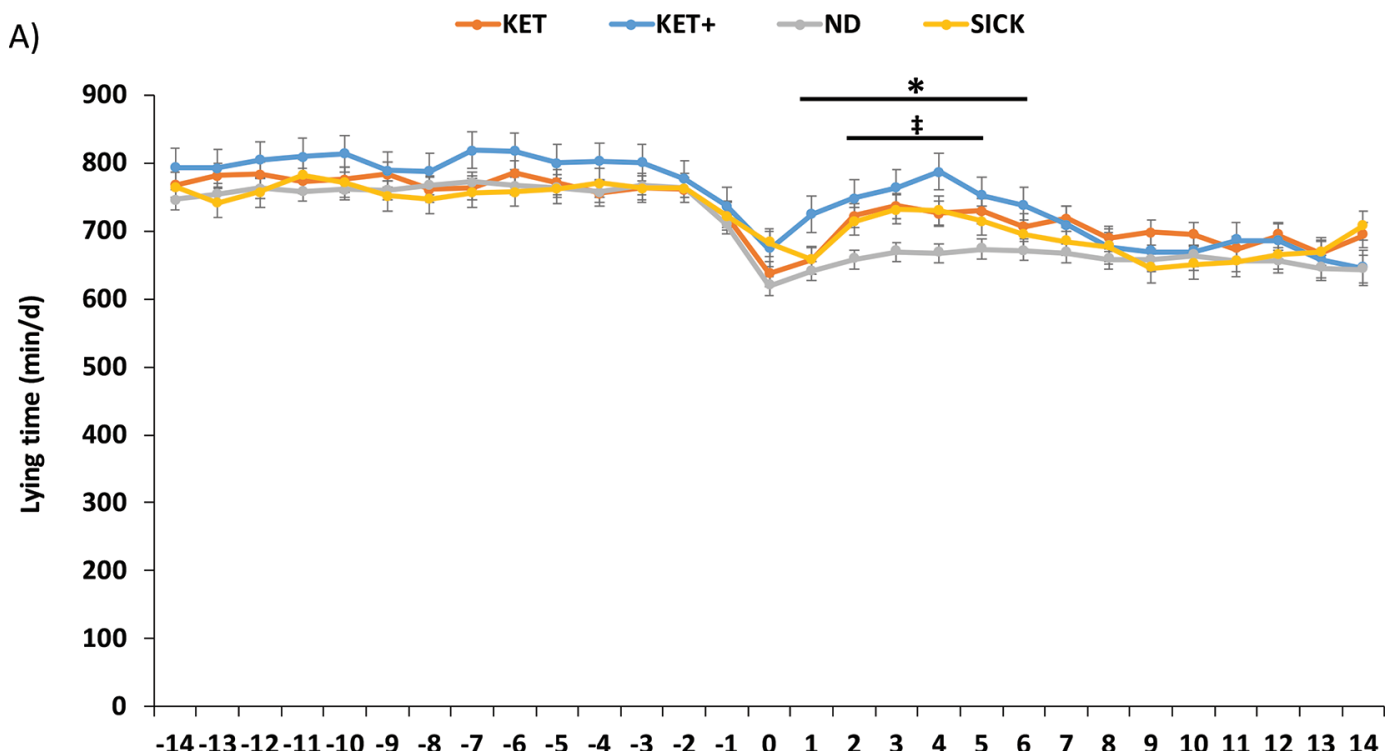

B)

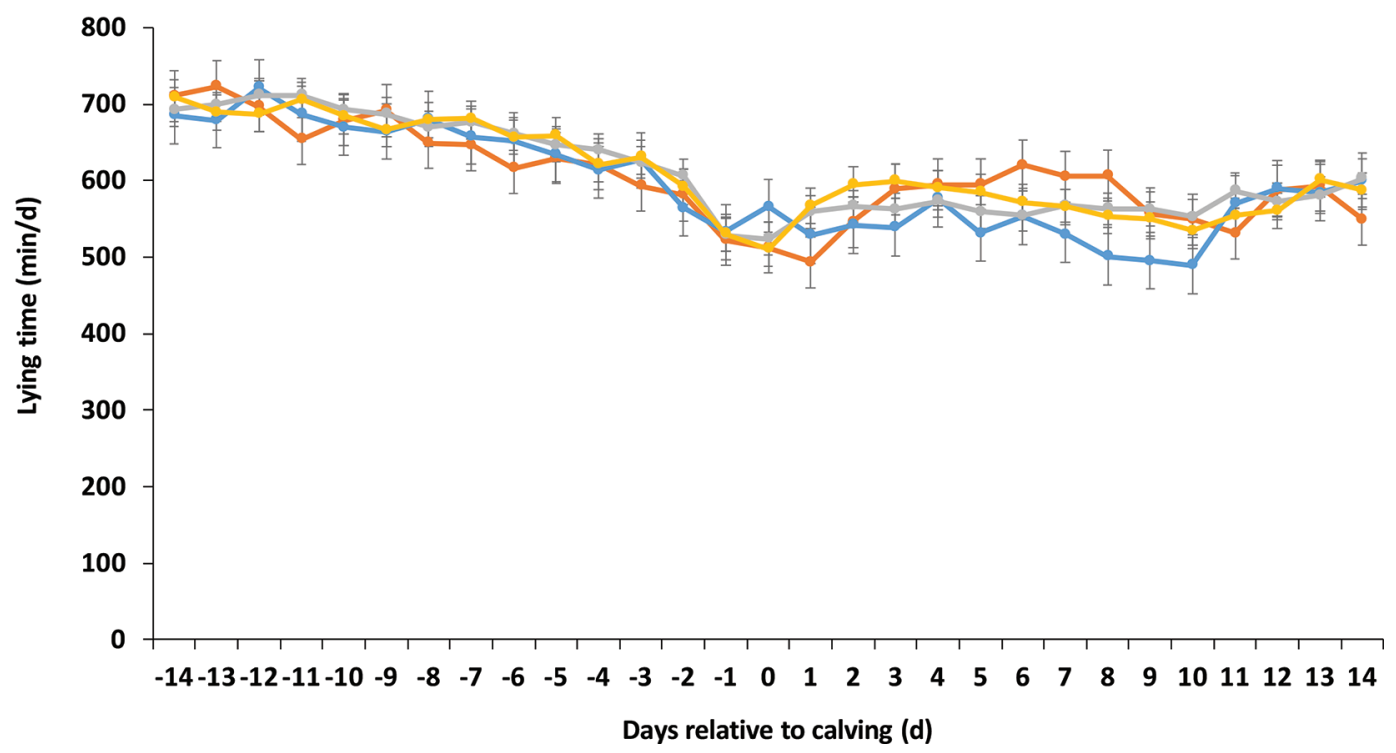

Figure 3. Least squares means $( \pm \mathrm{SEM})$ of lying time $(\mathrm{LT} ; \mathrm{min} / \mathrm{d})$ in Holstein dairy cows $(\mathrm{A}=$ multiparous and $\mathrm{B}=$ primiparous $)$ during the pre- and postpartum period by health status. Lactating dairy cows were classified into 1 of 4 groups with regard to their health status: (1) nondiseased ( $\mathrm{ND}, \mathrm{n}=613$; cows without ketosis or any other health conditions), (2) cows diagnosed with only ketosis (KET, $\mathrm{n}=152)$, (3) cows experiencing $\geq 1$ health conditions, but without ketosis (SICK, $\mathrm{n}=198$ ), or $(4)$ cows with ketosis plus at least one health condition $(\mathrm{KET}+, \mathrm{n}=$ 61). Multiparous KET + cows had significantly greater $(* P<0.001)$ LT compared with ND cows from d 1 to 6 after calving. Multiparous KET and SICK cows had significantly greater $(\ddagger P<0.001)$ LT compared with ND cows from d 2 to 4 after calving.

not significantly associated $(P=0.44)$ with serum $\mathrm{Ca}$ concentrations $(<$ or $\geq 8.0 \mathrm{mg} / \mathrm{dL})$ within $48 \mathrm{~h}$ after calving. Conversely, prepartum LT had a positive quadratic association with serum NEFA concentrations at $14 \pm 3 \mathrm{dpp}(P=0.0001)$ and $7 \pm 3 \operatorname{dpp}(P=0.0049$; Figure 4). In addition, mean LT during the first 14 DIM after parturition had a significant linear association $(P$
$=0.02$ ) with ketosis diagnosis within 14 DIM (Figure 5). For every 1-h increment of mean LT (from 8 to 15 $\mathrm{h} / \mathrm{d}$ ) within the first 14 DIM after calving, the risk of diagnosis with ketosis within 14 DIM increased by 3.7 percentage points (Figure 5). Lying time within 14 DIM was not significantly associated with haptoglobin $(P=0.81)$ or neutrophil count $(P=0.61)$. 
Association of Health Status with BCS Loss, NEFA, Calcium, and Inflammation

Regardless of parity, a greater proportion of KET and KET + cows had increased serum NEFA concentrations $(\geq 400 \mu \mathrm{Eq} / \mathrm{L})$ prepartum and increased BCS loss from -14 to 28 DIM compared with ND cows (Table $5)$. When assessing the association of hypocalcemia with health status, we detected a significant interaction $(P<0.0001)$ between health status and parity (lactation $=1$ vs. lactation $\geq 2$ ). A greater proportion of multiparous cows from the KET and KET+ group had hypocalcemia $(P=0.004)$ within $2 \mathrm{~d}$ after calving compared with ND and SICK cows, but there was no significant association $(P=0.19)$ between hypocalcemia and health status in primiparous cows.

Regarding the blood hemogram, we detected a significant interaction $(P<0.0001)$ between health status and parity. Multiparous KET + cows had significantly reduced $(P=0003)$ neutrophils and WBCC compared with ND cows, but lymphocytes did not differ (Table $5)$. However, health status was not significantly associated with neutrophils, lymphocyte, or total WBCC in primiparous cows (Table 5). Regardless of parity, KET + cows had a significantly higher concentration of serum haptoglobin compared with ND cows (Table 5). For multiparous cows, health status was significantly associated with neutrophils and total WBCC (Table 5).

\section{DISCUSSION}

The primary findings from the study are as follows. (1) Prepartum LT had a positive quadratic association with NEFA concentration, and lactating cows experiencing KET and KET+ had increased NEFA and greater BCS loss than ND cows, regardless of parity. (2) Multiparous cows experiencing KET, KET+, or SICK had significantly increased LT within the first 6 DIM after calving compared with ND cows. (3) Multiparous SICK and KET+ lactating cows had increased inflammatory response with decreased neutrophil count and increased serum haptoglobin compared with ND cows. (4) Primiparous SICK and KET+ lactating cows had increased haptoglobin compared with ND cows, but neutrophil, lymphocytes, and total WBCC did not differ. (5) A greater proportion of multiparous KET and

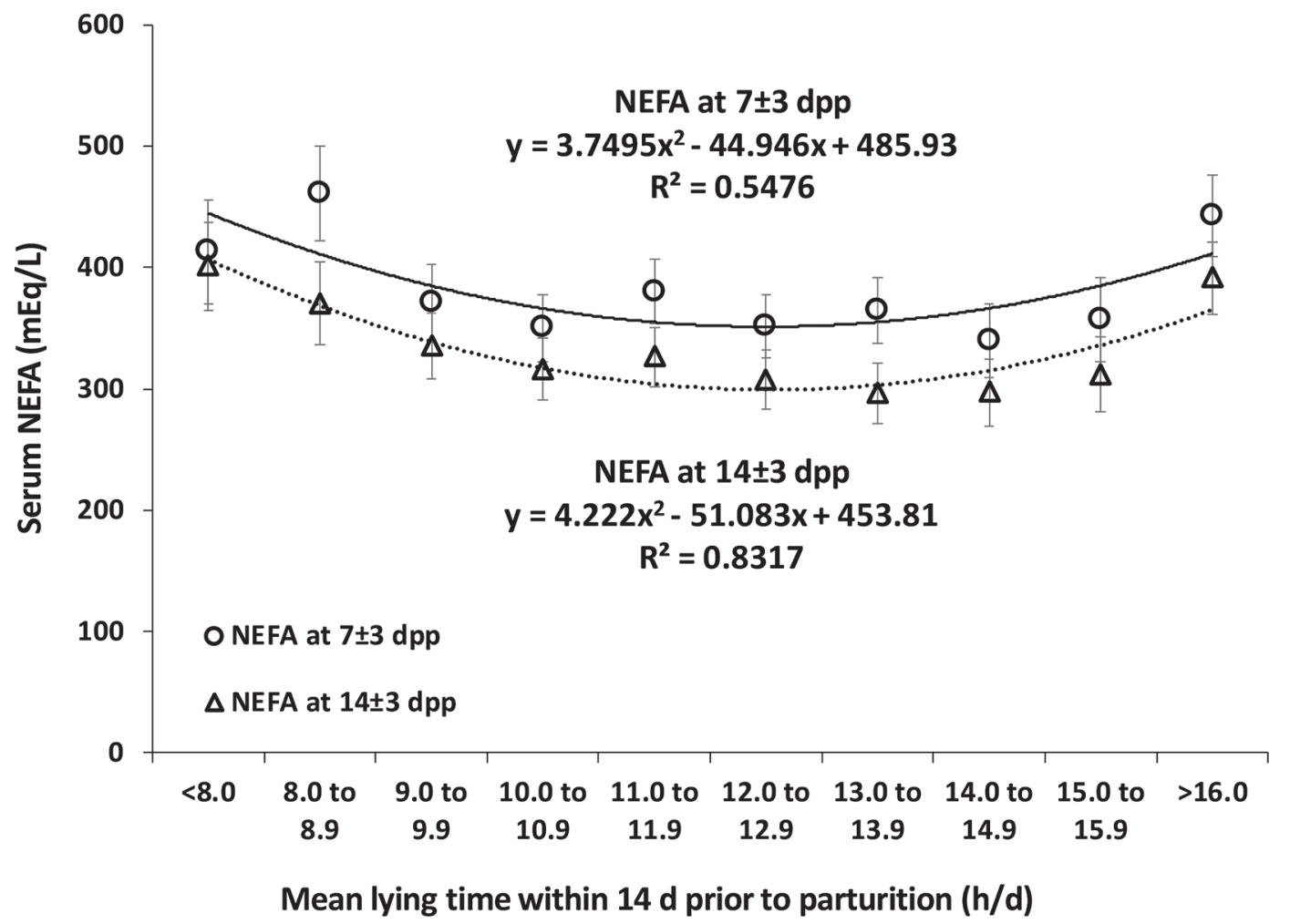

Figure 4. Least squares means $( \pm$ SEM) of lying time (LT) within $14 \mathrm{~d}$ prepartum (dpp) by hour intervals and serum nonesterified fatty acid (NEFA) concentration at $14 \pm 3$ and $7 \pm 3$ dpp from prepartum dairy heifers and cows. Blood samples were collected at $14 \pm 3$ and $7 \pm 3$ dpp to assess serum NEFA concentration in prepartum Holstein heifers and cows. Prepartum LT had a positive quadratic association with serum NEFA concentration at $14 \pm 3 \mathrm{dpp}(P=0.0001)$ and at $7 \pm 3 \mathrm{dpp}(P=0.0049)$. The LSM of lying time by hour intervals were obtained from the final model and plotted against serum NEFA at $14 \pm 3$ and at $7 \pm 3$ dpp. Each point (triangles and circles) represent the mean NEFA for the group of animals within the interval of hours per day. 
KET + cows had hypocalcemia within $2 \mathrm{~d}$ after calving compared with ND and SICK, but no differences were observed in primiparous cows.

Regardless of parity, lactating dairy cows experiencing KET or KET+ had elevated prepartum serum NEFA and greater body condition loss from -2 to 4 wk relative to parturition compared with ND cows. Increased prepartum NEFA concentration has been associated with early postpartum lactating cows experiencing ketosis (McArt et al., 2012a), metritis (Ospina et al., 2013), displaced abomasum (LeBlanc et al., 2005), and reduced reproductive performance (Ospina et al., 2013). Prepartum LT of animals had a positive quadratic response with NEFA concentration; cows with reduced (less than $9 \mathrm{~h} / \mathrm{d}$ ) or increased LT (greater than $15 \mathrm{~h} / \mathrm{d}$ ) had the highest NEFA concentration at $14 \pm 3$ and $7 \pm 3$ dpp. Perhaps prepartum animals with reduced LT are experiencing distress (Munksgaard and Simonsen, 1996) because of wet bedding or empty feed bunk (e.g., feed availability within reach at the bunk) and spending more time standing and mobilizing body fat in response to these stressors (Munksgaard and Si- monsen, 1996). It has been shown that lame prepartum cows have greater LT with elevated postpartum BHB compared with nonlame cows but not necessarily increased prepartum NEFA (Calderon and Cook, 2011). In dairy cows, LT increases with age and BW (Steensels et al., 2012). The prepartum cows with increased LT may have been either mature cows or simply cows experiencing a disease event (e.g., pneumonia, mastitis; Melendez et al., 2009).

The association of increased LT during the first week after calving with multiparous cows that experienced ketosis and at least another disease (KET+) compared with nondiseased cows has been previously reported (Kaufman et al., 2016). However, the present study also showed a significant increase in LT within 2 to $4 \mathrm{~d}$ after calving in multiparous cows experiencing only ketosis (KET) or other disease within $4 \mathrm{wk}$ after calving (SICK) compared with ND cows. Perhaps these observed differences from the Kaufman et al. (2016) study are due to the greater sample size and control of the confounding effect of locomotion score at enrollment (lameness) in the present study. Because

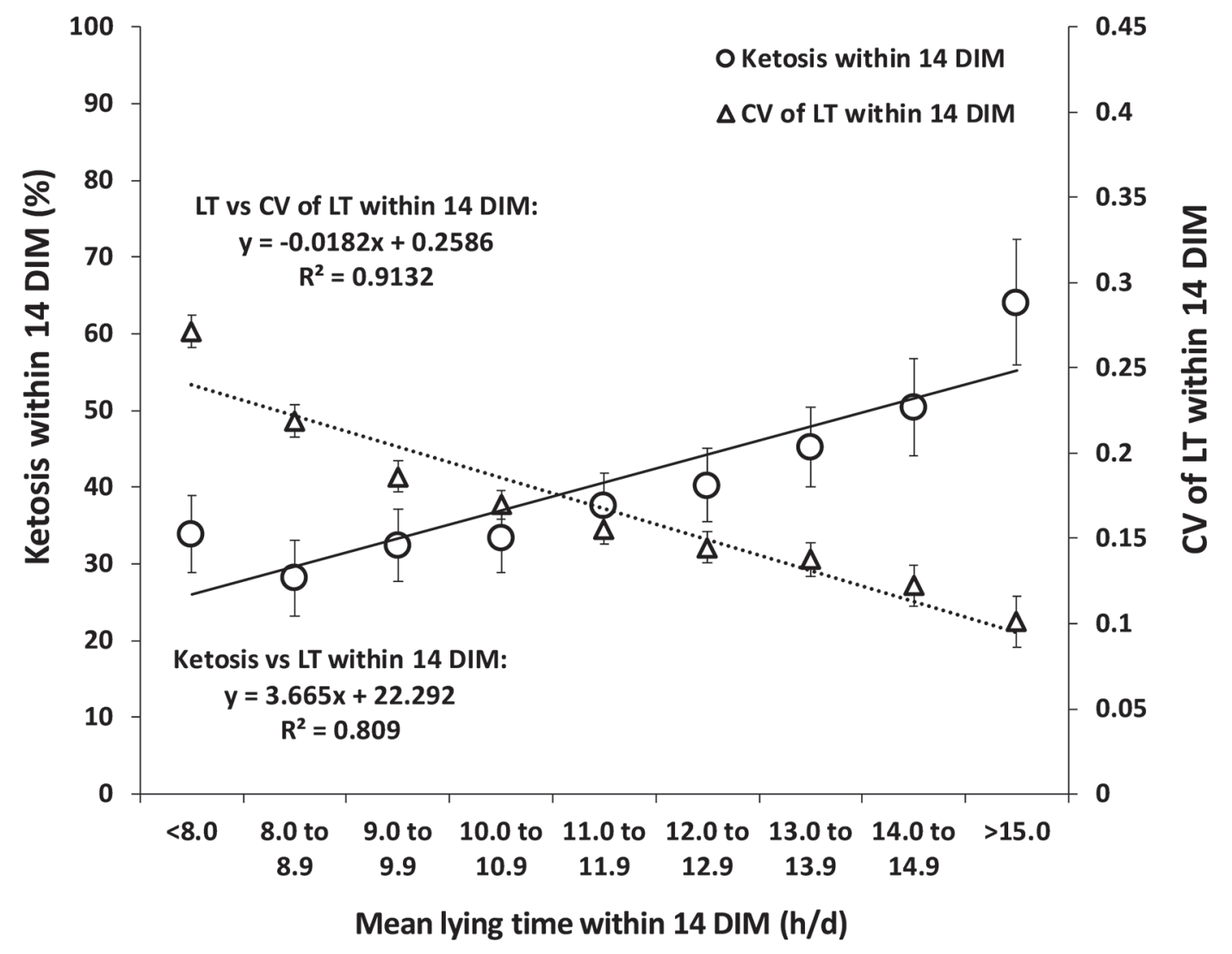

Figure 5. Least squares means ( \pm SEM) of lying time (LT) within the first 14 DIM by ketosis status $(\%)$ and the mean coefficient of variation (CV) of LT within 14 DIM. Blood samples were collected at $7 \pm 3$ and $14 \pm 3$ DIM to assess the proportion of Holstein dairy cows with ketosis $(\geq 1.2 \mathrm{mmol} / \mathrm{L})$. The LSM of LT by hour intervals were obtained from the final model and plotted against ketosis $(\%)$ and the CV of LT within the first 14 DIM after calving. Each point (triangles and circles) represents the mean NEFA for the group of animals within the interval of $\mathrm{LT}(\mathrm{h} / \mathrm{d})$. 
PIÑEIRO ET AL.

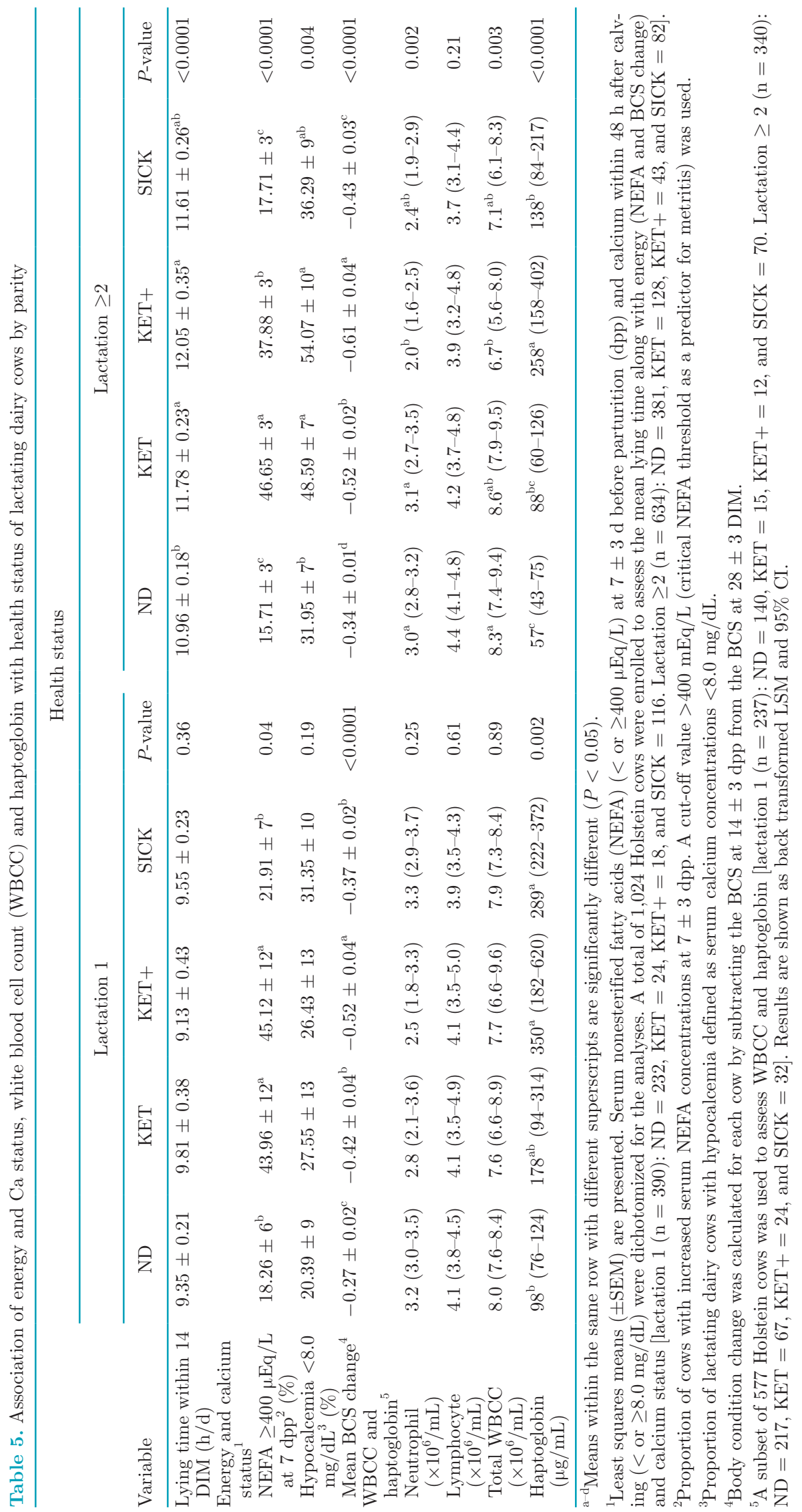


of the study design, we were unable to diagnose the onset of ketosis in lactating cows; thus, it is not possible to determine whether the increased LT caused the ketosis or vice versa. Because ketosis was assessed at $7 \pm 3$ and $14 \pm 3$ DIM, misclassification bias is possible for cases of ketosis that could have occurred after the first blood sample was taken and resolved before obtaining the second blood sample. Typically, ketosis occurs early in lactation with the greatest incidence of subclinical ketosis within 3 to 6 DIM (McArt et al., 2012b). Although disease diagnosis was performed by trained farm personnel, the frequency of screening and accuracy of diagnosis were not strictly controlled by the researchers. Therefore, it is likely that diseases such as pneumonia or mastitis were underdiagnosed in the present study. However, the researchers used markers of energy status (BHB), total serum $\mathrm{Ca}$, and systemic inflammation (haptoglobin) to complement the diagnosis of health disorders. It could be speculated that the acute inflammatory response in SICK and KET+ cows from the present study increased their LT (sickness behavior; Johnson 2002) and cows spent less time standing and eating at the feed bunk, resulting in both decreased daily feeding time and daily DMI. Johnston and DeVries (2018) showed that DMI increases by $1 \mathrm{~kg}$ for every $1-\mathrm{h}$ increment in feeding time. In addition, an acutely activated immune system increases glucose consumption by more than $1 \mathrm{~kg}$ per $12 \mathrm{~h}$, thus decreasing lactose and milk production (Kvidera et al., 2017). These events combined would result in increased fat mobilization, decreased intermediate metabolites from the tricarboxylic acid cycle, and increased blood concentration of ketone bodies.

Regarding SICK cows, the increased LT within 2 to 4 DIM might have preceded, in most cases, the onset of the disease event. Although we were unable to determine the onset of metritis because cows were screened at $7 \pm 3 \mathrm{DIM}$, the greatest incidence of metritis typically occurs between 4 and 9 DIM (Galvão, 2012); in the present study, metritis was the most prevalent infectious disease for SICK cows (150 unique cases out of 198 cows). Huzzey et al. (2007) showed that lactating cows with severe metritis had decreased daily feeding time and DMI shortly after calving. Perhaps, in the present study, cows with increased LT on d 2, 3, and 4 after calving also had decreased feeding time and DMI, exacerbating the increased negative energy and calcium balance early in lactation. In turn, these metabolic alterations might have impaired the immune system and predisposed cows to infectious diseases (Hammon et al., 2006; Kimura et al., 2006). It has been shown that lactating cows experiencing metritis have neutrophils with impaired killing ability during the first 2 wk after calving and before the onset of the disease, around parturition (Hammon et al., 2006).

Regardless of parity, lactating SICK and KET+ cows had an increased inflammatory response, as indicated by an increased concentration of serum haptoglobin. These findings are in alignment with previous studies reporting a significant increase in serum haptoglobin in lactating cows experiencing metritis (Huzzey et al., 2009) or mastitis (Grönlund et al., 2005). Lactating dairy cows experiencing metritis have been shown to have elevated concentrations of serum haptoglobin, a positive hepatic phase acute protein and indicator of inflammation (Dubuc et al., 2010a; Pohl et al., 2015). Furthermore, lactating dairy cows experiencing ketosis, metritis, or both had reduced milk yield and reproductive performance (Ospina et al., 2013). These diseased cows likely have an activated immune system with increased inflammation, which requires a large amount of glucose to repair damaged tissue (Kvidera et al., 2017); thus, explaining the subsequent drop in milk yield. In addition, multiparous KET+ cows had reduced neutrophil counts compared with ND cows. The neutrophil count during inflammation processes depends on a balance between the migration of neutrophils to the lesion and the production and release from the bone marrow (Thrall et al., 2012). Because bovines have a low marrow reserve and low regenerative capacity of neutrophils compared with other species, the most common leukogram response during acute inflammations is neutropenia, which can last for several days (Thrall et al., 2012). In fact, neutropenia occurs frequently in bovines with acute inflammatory diseases such as metritis, mastitis, pneumonia, gastrointestinal diseases, and peritonitis, among others (Weiss and Wardrop, 2011). Although a similar response was observed with primiparous KET + cows having the lowest count of neutrophils, we detected no significant differences in neutrophil count among health groups of primiparous cows. This difference between parity groups could be attributed to a less responsive or immature immune system of primiparous cows, whereas neutrophils from multiparous cows would respond more efficiently with greater migration to the inflamed tissue. Regardless of health status, primiparous cows experience a greater inflammatory response than multiparous cows during the early postpartum (Humblet et al., 2006). In addition, previous research showed that primiparous cows experiencing metritis have increased lying time compared with nondiseased cows, but no differences were observed in multiparous cows, suggesting more expression of the sickness behavior in primiparous cows (Barragan et al., 2018). It is possible that primiparous cows have an exacerbated inflammatory response shortly after calving 
due to their first contact with antigens and, as they mature, they develop a more efficient immune response.

Multiparous KET and KET + cows had increased prevalence of hypocalcemia within $2 \mathrm{~d}$ after calving compared with ND and SICK. These results are in agreement with previous research that found that cows with subclinical hypocalcemia are 5.5 times more likely to have ketosis (Rodríguez et al., 2017); and cows with clinical hypocalcemia are 8.9 times more likely to experience ketosis (Curtis et al., 1983). This could be partially explained by the decrease in DMI (Martinez et al., 2012) or increased calcium demand to support lipomobilization early in lactation (act as a cofactor for enzyme reactions). A previous study showed a $42 \%$ decrease in DMI in lactating cows with induced subclinical hypocalcemia (Martinez et al., 2014). Conversely, no differences were observed in the proportion of primiparous cows with hypocalcemia within $2 \mathrm{~d}$ after calving between different health groups. However, only $19.9 \%$ of primiparous cows had hypocalcemia, whereas $42.3 \%$ of multiparous cows had hypocalcemia. Therefore, our declaration of nonsignificance in primiparous cows might be due to lack of statistical power.

The present study focused on the associations of preand postpartum LT on metabolic status, inflammation, and heath events, while analytically controlling for cow(e.g., parity, LS, and BCS at enrollment) and herd-level confounders (e.g., season). However, there is scant information in the literature about the effect of herd-level factors (e.g., hours of empty feed bunk, bedding frequency, cow movement) on LT, health, and performance of dairy cows. Further research is needed to assess the association of LT of transition heifers and cows with bedding management (e.g., type and maintenance), changes in DM content of feed (e.g., corn silage) due to rainy days, feed availability at the bunk, dynamics of stocking density within groups, logistics of implementing health protocols, and milking frequency early in lactation with DMI and its implications for health and performance. In the present study, prepartum LT was not associated with postpartum KET, KET+, or SICK. Perhaps the assessment of individual health events such as metritis may reveal a distinct LT behavior during the pre- and early postpartum period. Lactating dairy cows with severe metritis spent less time feeding and consumed less feed compared with nondisease cows during the week before and after parturition (Huzzey et al., 2007). The success of transition cow management relies on several preventive and consistent management practices to achieve optimal performance of lactating cows and, thus, profitability and welfare of the herd. Perhaps the best or most successful dairy farms (in terms of longevity, reproductive performance, and milk quality) have achieved consistent management over time by implementing a simple but effective transition program able to control these variables. Future studies should assess the consistency of LT through the CV of LT over time, along with energy and calcium balance, to help identify key management and housing practices associated with health and performance of transition dairy heifers and cows.

\section{CONCLUSIONS}

Our results suggest that LT along with energy (NEFA and $\mathrm{BHB}$ ) and Ca balance are critical for transition cow health. Prepartum NEFA had a positive quadratic association with prepartum LT. Multiparous lactating cows had increased LT concomitant with their postpartum health events. Primiparous cows spent more time standing during the transition period and showed a different behavioral response to sickness than multiparous cows.

\section{ACKNOWLEDGMENTS}

Collaborating dairy farms and their staff are greatly appreciated for providing the animals used in the present study; we are also grateful to graduate and undergraduate students for their assistance during the project. Also, the laboratory support from D. J. Wyatt (The Ohio State University, Wooster) and D. Mollenkopf (The Ohio State University, Columbus) as well as the valuable suggestions from Greg Habing and Luciana da Costa (The Ohio State University, Columbus) are greatly appreciated. This project was partially supported by Veterinary Extension at The Ohio State University, College of Veterinary Medicine.

\section{REFERENCES}

Allen, M. S. 1997. Relationship between fermentation acid production in the rumen and the requirement for physically effective fiber. J. Dairy Sci. 80:1447-1462.

Barragan, A. A., J. M. Piñeiro, G. M. Schuenemann, P. J. RajalaSchultz, D. E. Sanders, J. Lakritz, and S. Bas. 2018. Assessment of daily activity patterns and biomarkers of pain, inflammation, and stress in lactating dairy cows diagnosed with clinical metritis. J. Dairy Sci. 101:8248-8258.

Calderon, D. F., and N. B. Cook. 2011. The effect of lameness on the resting behavior and metabolic status of dairy cattle during the transition period in a freestall-housed dairy herd. J. Dairy Sci. 94:2883-2894.

Curtis, C. R., H. N. Erb, C. J. Sniffen, R. D. Smith, P. A. Powers, M. C. Smith, M. E. White, R. B. Hillman, and E. J. Pearson. 1983. Association of parturient hypocalcemia with eight periparturient disorders in Holstein cows. J. Am. Vet. Med. Assoc. 183:559-561.

Dubuc, J., T. F. Duffield, K. E. Leslie, J. S. Walton, and S. J. LeBlanc. 2010. Risk factors for postpartum uterine diseases in dairy cows. J. Dairy Sci. 93:5764-5771.

Ferguson, J. D. 2005. Nutrition and reproduction in dairy herds. Vet. Clin. North Am. Food Anim. Pract. 21:325-347. 
Ferguson, J. D., D. T. Galligan, and N. Thomsen. 1994. Principal descriptors of body condition score in Holstein cows. J. Dairy Sci. 77:2695-2703.

Galindo, F., and D. M. Broom. 2000. The relationships between social behaviour of dairy cows and the occurrence of lameness in three herds. Res. Vet. Sci. 69:75-79.

Galvão, K. N. 2012. Postpartum uterine diseases in dairy cows. Anim. Reprod. Sci. 9:290-296.

Gohary, K., M. W. Overton, M. Von Massow, S. J. LeBlanc, K. D. Lissemore, and T. F. Duffield. 2016. The cost of a case of subclinical ketosis in Canadian dairy herds. Can. Vet. J. 57:728-732.

Gomez, A., and N. B. Cook. 2010. Time budgets of lactating dairy cattle in commercial freestall herds. J. Dairy Sci. 93:5772-5781.

Grönlund, U., C. H. Sandgren, and K. P. Waller. 2005. Haptoglobin and serum amyloid A in milk from dairy cows with chronic subclinical mastitis. Vet. Res. 36:191-198.

Hammon, D. S., I. M. Evjen, T. R. Dhiman, J. P. Goff, and J. L. Walters. 2006. Neutrophil function and energy status in Holstein cows with uterine health disorders. Vet. Immunol. Immunopathol. 113:21-29.

Humblet, M. F., H. Guyot, B. Boudry, F. Mbayahi, C. Hanzen, F. Rollin, and J. M. Godeau. 2006. Relationship between haptoglobin, serum amyloid $\mathrm{A}$, and clinical status in a survey of dairy herds during a 6-month period. Vet. Clin. Pathol. 35:188-193.

Huzzey, J. M., T. F. Duffield, S. J. LeBlanc, D. M. Veira, D. M. Weary, and M. A. G. von Keyserlingk. 2009. Short communication: Haptoglobin as an early indicator of metritis. J. Dairy Sci. 92:621-625.

Huzzey, J. M., D. M. Veira, D. M. Weary, and M. A. G. von Keyserlingk. 2007. Prepartum behavior and dry matter intake identify dairy cows at risk for metritis. J. Dairy Sci. 90:3220-3233.

Johnson, R. W. 2002. The concept of sickness behavior: a brief chronological account of four key discoveries. Vet. Immunol. Immunopathol. 87:443-450.

Johnston, C., and T. J. DeVries. 2018. Short communication: Associations of feeding behavior and milk production in dairy cows. J. Dairy Sci. 101:3367-3373.

Kaufman, E. I., S. J. LeBlanc, B. W. McBride, T. F. Duffield, and T. J. DeVries. 2016. Short communication: Association of lying behavior and subclinical ketosis in transition dairy cows. J. Dairy Sci. 99:7473-7480.

Kimura, K., T. A. Reinhardt, and J. P. Goff. 2006. Parturition and hypocalcemia blunts calcium signals in immune cells of dairy cattle. J. Dairy Sci. 89:2588-2595.

Kvidera, S. K., E. A. Horst, M. Abuajamieh, E. J. Mayorga, M. V. Sanz Fernandez, and L. H. Baumgard. 2017. Glucose requirements of an activated immune system in lactating Holstein cows. J. Dairy Sci. 100:2360-2374.

LeBlanc, S. J., K. E. Leslie, and T. F. Duffield. 2005. Metabolic predictors of displaced abomasum in dairy cattle. J. Dairy Sci. 88:159-170.

LeBlanc, S. J., K. D. Lissemore, D. F. Kelton, T. F. Duffield, and K. E. Leslie. 2006. Major Advances in Disease Prevention in Dairy Cattle. J. Dairy Sci. 89:1267-1279.

Martinez, N., C. A. Risco, F. S. Lima, R. S. Bisinotto, L. F. Greco, E. S. Ribeiro, F. Maunsell, K. Galvão, and J. E. Santos. 2012. Evaluation of peripartal calcium status, energetic profile, and neutrophil function in dairy cows at low or high risk of developing uterine disease. J. Dairy Sci. 95:7158-7172.

Martinez, N., L. D. P. Sinedino, R. S. Bisinotto, E. S. Ribeiro, G. C. Gomes, F. S. Lima, L. F. Greco, C. A. Risco, K. N. Galvão, D. Taylor-Rodriguez, J. P. Driver, W. W. Thatcher, and J. E. P. Santos. 2014. Effect of induced subclinical hypocalcemia on physiological responses and neutrophil function in dairy cows. J. Dairy Sci. 97:874-887.

McArt, J. A. A., D. V. Nydam, and G. R. Oetzel. 2012a. A field trial on the effect of propylene glycol on displaced abomasum, removal from herd, and reproduction in fresh cows diagnosed with subclínical ketosis. J. Dairy Sci. 95:2505-2512.

McArt, J. A. A., D. V. Nydam, and G. R. Oetzel. 2012b. Epidemiology of subclinical ketosis in early lactation dairy cattle. J. Dairy Sci. 95:5056-5066.
Melendez, P., M. P. Marin, J. Robles, C. Rios, M. Duchens, and L. Archbald. 2009. Relationship between serum nonesterified fatty acids at calving and the incidence of periparturient diseases in Holstein dairy cows. Theriogenology 72:826-833.

Munksgaard, L., M. B. Jensen, L. J. Pedersen, S. W. Hansen, and L. Matthews. 2005. Quantifying behavioural priorities - effects of time constraints on behaviour of dairy cows, Bos taurus. Appl. Anim. Behav. Sci. 92:3-14.

Munksgaard, L., and P. Løvendahl. 1993. Effects of social and physical stressors on growth hormone levels in dairy cows. Can. J. Anim. Sci. 73:847-853.

Munksgaard, L., and H. B. Simonsen. 1996. Behavioral and pituitary adrenal-axis responses of dairy cows to social isolation and deprivation of lying down. J. Anim. Sci. 74:769-778.

National Research Council. 2001. Nutrient Requirements of Dairy Cattle. 7th rev. ed. National Academy Press, Washington, DC

Ospina, P. A., J. A. McArt, T. R. Oberton, T. Stokol, and D. V. Nydam. 2013. Using nonesterified fatty acids and $\beta$-hydroxybutyrate concentrations during the transition period for herd-level monitoring of increased risk of disease and decreased reproductive and milking performance. Vet. Clin. North Am. Food Anim. Pract. 29:387-412.

Pohl, A., O. Burfeind, and W. Heuwieser. 2015. The associations between postpartum serum haptoglobin concentration and metabolic status, calving difficulties, retained fetal membranes, and metritis. J. Dairy Sci. 98:4544-4551.

Reinhardt, T. A., J. D. Lippolis, B. J. McCluskey, J. P. Goff, and R. L. Horst. 2011. Prevalence of subclinical hypocalcemia in dairy herds. Vet. J. 188:122-124.

Rodríguez, E. M., A. Arís, and A. Bach. 2017. Associations between subclinical hypocalcemia and postparturient diseases in dairy cows. J. Dairy Sci. 100:7427-7434.

Rollin, E., K. C. Dhuyvetter, and M. W. Overton. 2015. The cost of clinical mastitis in the first 30 days of lactation: An economic modeling tool. Prev. Vet. Med. 122:257-264.

SAS Institute. 2014. SAS/STAT 9.2 User's Guide. 2nd ed. SAS Institute Inc., Cary, NC.

Schuenemann, G. M., I. Nieto, S. Bas, K. N. Galvão, and J. Workman. 2011. Assessment of calving progress and reference times for obstetric intervention during dystocia in Holstein dairy cows. J. Dairy Sci. 94:5494-5501.

Sheldon, I. M., G. S. Lewis, S. LeBlanc, and R. O. Gilbert. 2006. Defining postpartum uterine disease in cattle. Theriogenology 65:1516-1530.

Steensels, M., C. Bahr, D. Berckmans, I. Halachmi, A. Antler, and E. Maltz. 2012. Lying patterns of high producing healthy dairy cows after calving in commercial herds as affected by age, environmental conditions and production. Appl. Anim. Behav. Sci. 136:88-95.

Thrall, M. A., G. Weiser, R. Allison, and T. Campbell. 2012. Hematology of Common Domestic Species. Pages 206-223 in Veterinary Hematology and Clinical Chemistry. 2nd ed. John Wiley \& Sons Inc., Ames, IA.

Vieira-Neto, A., K. N. Galvão, W. W. Thatcher, and J. E. P. Santos. 2017. Association among gestation length and health, production, and reproduction in Holstein cows and implications for their offspring. J. Dairy Sci. 100:3166-3181.

Walker, S. L., R. F. Smith, J. E. Routly, D. N. Jones, M. J. Morris, and H. Dobson. 2008. Lameness, activity time-budgets, and estrus expression in dairy cattle. J. Dairy Sci. 91:4552-4559.

Weiss, D. J., and K. J. Wardrop. 2011. Interpretation of Ruminant Leukocyte Responses. Pages 307-310 in Schalm's Veterinary Hematology. 6th ed. John Wiley \& Sons, Inc. Ames, Iowa.

Zarrin, M., O. Wellnitz, H. A. van Dorland, and R. M. Bruckmaier. 2014. Induced hyperketonemia affects the mammary immune response during lipopolysaccharide challenge in dairy cows. J. Dairy Sci. 97:330-339. 